\title{
Cerebral atrophy in motor neuron disease evaluated by computed tomography
}

\author{
MARCO POLONI, CARLO MASCHERPA, LUIGI FAGGI, FELICE ROGNONE, * \\ LUIGI GOZZOLI*
}

\author{
From the Institute of Clinical Neurology and Section of Neuroradiology, ${ }^{*}$ University of Pavia, Pavia, Italy
}

SUMMARY Thirty-two $(64 \%)$ of 50 patients with motor neuron disease showed various patterns of cerebral atrophy (cortical, ventricular or both) at CT examination. The incidence of cerebral atrophy, particularly cortical atrophy, in motor neuron disease was greater than in a matched control group.

Involvement of the cerebral cortex in motor neuron disease was first described by Pierre Marie in 1883 and then was recognised by a number of authors. ${ }^{1-3}$ Pathological changes were described mainly in motor, premotor and opercular regions, consisting of a reduction in number and degeneration of giant pyramidal cells of Betz. ${ }^{4}$ A reduction in the weight of the cerebral hemispheres with frontal lobe atrophy, ${ }^{5}$ and extensive degeneration involving several cortical regions and cerebral structures such as the thalamus, corpus striatum, subthalamic nucleus and substantia nigra have also been reported.$^{67}$ More recently, the similarity between the type of neuronal degeneration in motor neuron disease and that seen in normal aging has been pointed out. ${ }^{89}$

Computed tomography (CT) has now provided the opportunity to investigate this disorder by a noninvasive and safe method. Considerable efforts have been made to correlate the findings of cortical and/or ventricular atrophy to age-related changes in normal populations, ${ }^{1011}$ and to early disturbances of cognitive functions both in normal people ${ }^{12}$ and in demented patients. ${ }^{13-15}$ Brain atrophy revealed by CT has been also investigated in various neurological conditions such as Parkinson's disease ${ }^{16}$ and hereditary ataxias. ${ }^{17}$ In the present report we have studied the presence of cerebral atrophy at CT examination in motor neuron disease patients and its possible relationship with the clinical variables of the disease.

Address for reprint requests to: Dr M Poloni, Neurological Clinic, Via Palestro 3, 27100 Pavia, Italy.

Received 8 February 1982 and in final revised form 8 August 1982. Accepted 31 August 1982

\section{Materials and methods}

Fifty patients with motor neuron disease (mean duration 20 months) have been investigated. The control group consisted of 50 subjects of matched age and sex examined by CT either for minor neurological problems (headache or vertigo: 30 cases) or for possible vascular disease (10 cases) and seizures (10 cases). Data concerning the sex and mean age of motor neuron disease and control patients are summarised in table 1.

The patients have been divided into the following four groups, according to the classification suggested by Engel ${ }^{18}$ : 1 = typical motor neuron disease (24 subjects), $2=$ upper motor neuron involvement (nine subjects displaying increased tone, hyperreflexia, mild or severe upper motor neuron paresis), 3 = lower motor neuron involvement (six subjects manifested by lower motor neuron signs alone), 4 = bulbar or pseudobulbar involvement (11 subjects predominantly with atrophy and weakness of cranial muscles).

CT was performed in all the cases using an EMI 1010, with an angle of $20^{\circ}$ with the orbitomeatal line. The following assessments were made: (a) lateral ventricle dimensions were obtained by calculating the distance between the most lateral portion of each frontal horn (bifrontal diameter), and the width of the lateral ventricles in the region of the caudate nucleus (bicaudate diameter); these two dimensions were summed according to

Table 1 Number of cases, sex and mean age (years) $\pm S D$ in motor neuron disease and control patients. There was no significant difference by Student's t test examination

\begin{tabular}{llllll}
\hline & \multicolumn{2}{l}{ Number of cases } & & \multicolumn{2}{l}{ Mean age $(y r) \pm S D$} \\
\cline { 2 - 3 } \cline { 5 - 6 } & males & females & & males & females \\
\hline $\begin{array}{l}\text { Motor neuron } \\
\text { disease } \\
\begin{array}{c}\text { patients } \\
\text { Controls }\end{array}\end{array}$ & 34 & 16 & & $53 \cdot 94 \pm 11 \cdot 28$ & $59 \cdot 93 \pm 5 \cdot 30$ \\
\hline
\end{tabular}


Huckman. ${ }^{15}$ (b) Cortical atrophy was evaluated "blind" by two experienced neuroradiologists by summing the total width of the four largest cortical sulci seen in the highest three tomographic sections according to Huckman, ${ }^{15}$ and by giving a cortical atrophy score on a four point scale (none, mild, moderate, severe) for five cortical regions (frontal, parietal, temporal, insula, and occipital) in each hemisphere, according to Jacoby. ${ }^{11}$ For the purpose of statistical analysis, each patient and control subject was given a score for ventricular dimensions according to Huckman (VIH), a score for cortical atrophy according to Huckman (CAH) and a score for cortical atrophy as evaluated subjectively (CAS). The correlation coefficient between $\mathrm{CAH}$ and CAS showed a high correlation both in motor neuron disease $(r=0.7096 ; p<0.001)$ and controls $(r=0.5571 ; p<0.01)$. Patients showing a CAH score $>5$ $\mathrm{mm}$ and those displaying a CAS score $\geqslant 1$ were considered to have cortical atrophy. During the evaluation of the results the CAS score has been examined in detail, for it localises the affected region. Correlation coefficient ( $r$ ) and chi-square were calculated for the purpose of the statistical analysis, as well as Student's $t$ test for the comparison of the two groups.

\section{Results}

In the group of motor neuron disease patients, $36 \%$ had a normal score (CAS). $64 \%$ showed different patterns of cerebral atrophy: cortical $(30 \%)$ or global $(34 \%)$. In the control group, $54 \%$ were normal and $4 \%, 34 \%$ and $8 \%$ respectively displayed signs of cortical atrophy, ventricular enlargement or both. Table 2 shows the CAH, CAS and VIH scores in the two groups together with the statistical analysis.

In motor neuron disease, cortical atrophy affected preferentially the parietal $(50 \%)$, insulae $(38 \%)$, frontal $(32 \%)$, temporal $(20 \%)$, occipital (12\%) regions. It was bilateral or mutifocal in $80 \%$ of cases. Its degree was mainly mild or moderate, being severe in only $15 \%$ of cases. Ventricular enlargement was found in 17 cases (34\%), but in none was it isolated; the same incidence was observed in the control group. The distribution of motor neuron disease cases with cortical or ventricular atrophy (in percent) in different decades is shown in the figure. A

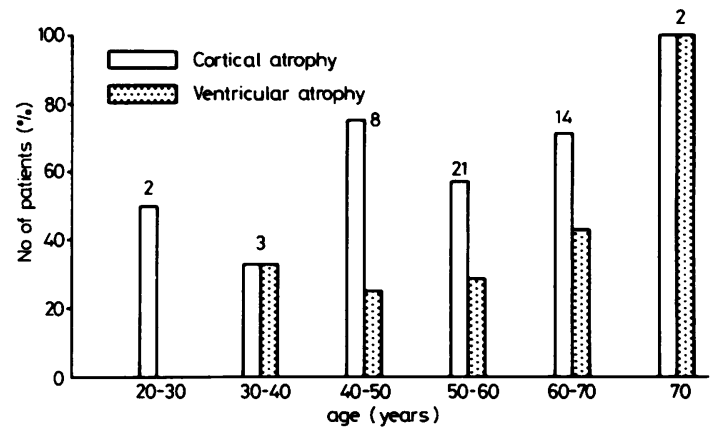

Fig Frequency of abnormal CT findings in motor neuron disease in relation to age; the number on the top of each bargraph indicates the number of patients in each decade; on the ordinate are the percentages of those numbers.

statistical comparison between subjects aged over and under 60 years did not show any significant difference $\left(\mathrm{X}^{2}=1 \cdot 2357 ; \mathrm{p}=\mathrm{NS}\right)$. The correlation coefficient between CAS and age was not significant ir. motor neuron disease or controls. Ventricular atrophy was present in $50 \%$ of motor neuron disease subjects aged over 60 years, and only in $26 \%$ of those younger; a significant correlation was found between VIH and age in motor neuron disease $(r=0.3356$; $0.05>p>0.02)$, and in controls $(r=0.3676 ; p<$ $0 \cdot 01$ ). Cortical and ventricular atrophy did not show any relationship with the duration of the disease. Cortical atrophy in motor neuron disease was associated in a statistically significant proportion $\left(\mathrm{X}^{2}\right.$ $=7 \cdot 171 ; 0.01>p>0.001)$ to the male sex; $76.5 \%$ of males and $36 \%$ of females exhibited atrophy. Ventricular enlargement did not show such a relation $\left(\mathrm{X}^{2}=2 \cdot 4385\right)$. This pattern was not observed in the control group.

Cortical atrophy appeared in $79 \%$ of typical motor neuron disease cases (19 of 24), in $72 \%$ of bulbar motor neuron disease cases (eight of 11 ), in $44 \%$ of upper motor neuron cases (four of nine) and only in $16 \%$ of lower motor neuron cases (one of six). Statistical analysis showed a significant association between cortical atrophy and cortico-spinal pathway

Table 2 Cortical atrophy according to Huckman (CAH), cortical atrophy subjectively evaluated (CAS) and ventricular dimension (VIH) scores (means $\pm S D$ ) in motor neuron disease patients (without atrophy, with cortical and with cortical + ventricular atrophy) and in control subjects

${ }^{*} p<0.01$ (Student's t test) as compared to controls

\begin{tabular}{|c|c|c|c|c|c|c|}
\hline \multirow[t]{2}{*}{ Motor neuron disease patients } & \multicolumn{3}{|c|}{ Number of cases } & \multirow[t]{2}{*}{$C A H(m m)$} & \multirow[t]{2}{*}{$C A S$} & \multirow[t]{2}{*}{$V I H(m m)$} \\
\hline & & & $1 \%$ & & & \\
\hline $\begin{array}{l}\text { Without atrophy } \\
\text { With cortical atrophy } \\
\text { With cortical and ventricular atrophy } \\
\text { Total motor neuron disease patients } \\
\text { Controls }\end{array}$ & $\begin{array}{l}10 \\
10 \\
14 \\
34 \\
34\end{array}$ & $\begin{array}{r}8 \\
5 \\
3 \\
16 \\
16\end{array}$ & $\begin{array}{l}36 \\
30 \\
34 \\
-\end{array}$ & $\begin{array}{l}2 \cdot 47 \pm 0 \cdot 84 \\
4 \cdot 46 \pm 1 \cdot 63 \\
5 \cdot 32 \pm 1 \cdot 77 \\
4 \cdot 04 \pm 1 \cdot 88^{*} \\
3 \cdot 36 \pm 1 \cdot 42\end{array}$ & $\begin{array}{l}0 \\
4 \cdot 20 \pm 2 \cdot 67 \\
9 \cdot 82 \pm 8 \cdot 27 \\
4 \cdot 60 \pm 6 \cdot 45^{*} \\
1 \cdot 84 \pm 4 \cdot 13\end{array}$ & $\begin{array}{l}13 \cdot 11 \pm 1 \cdot 52 \\
13 \cdot 20 \pm 1 \cdot 32 \\
18 \cdot 05 \pm 1 \cdot 81 \\
14 \cdot 82 \pm 2 \cdot 81 \\
15 \cdot 10 \pm 2 \cdot 03\end{array}$ \\
\hline
\end{tabular}


involvement in the first three motor neuron disease subtypes. Ventricular enlargement, on the other hand, did not appear to follow a similar distribution.

\section{Discussion}

The frequency of atrophic changes in the cortex of motor neuron disease patients was higher than in a control group both in objective and subjective measurements. If comparison is made between these $\mathrm{CT}$ results and previous reports on necropsy cases, ${ }^{57}$ $64 \%$ exhibited cortical atrophy and $34 \%$ ventricular enlargement on CT, as compared to $50 \%$ of the Lawyer ${ }^{5}$ necropsy series, and one-third of cases in the Bromwell ${ }^{7}$ necropsy series.

In the group of volunteers over the age of 60 years investigated by Jacoby, " the mean cortical atrophy score, calculated with the same criteria employed here, was $2.0 \pm 1.79(1.5$ in the seventh decade $; 2.0$ in the eighth decade and 3.2 in the ninth decade). The group studied here was considerably younger than this, but the mean score was clearly higher $(4 \cdot 6 \pm$ $6 \cdot 45$ ) and significantly different from that of controls of matched age $(1.84 \pm 4 \cdot 13)$. Ventricular dimensions were almost the same in motor neuron disease and control groups.

The regions with a high frequency of atrophic changes (frontai, parietal, insulae) are those of the sensori-motor cortex but, as already observed in pathological studies, ${ }^{57}$ cortical atrophy in motor neuron disease may be diffuse. This distribution does not seem to be different from that observed in other diseases of the central nervous system such as Parkinsonism ${ }^{16}$ or in the subjects chosen as controls.

Cortical atrophy was not correlated with age either in motor neuron disease or in control group. A positive relation between cortical atrophy and age has been found in elderly "normal" people" and in Parkinsonian patients, ${ }^{16}$ but not in senile dementia patients. ${ }^{19}$ A correlation was found for ventricular size and age in both groups. Ventricular atrophy tends to correlate better than cortical atrophy with age also in necropsy cases. ${ }^{20}$ These facts suggest a preferential relationship between cortical atrophy and disease. Ventricular atrophy, on the contrary, may be a collateral phenomenon determined by the physiologic processes of aging.

The frequency of appearance of cortical atrophy was higher in males than in females in motor neuron disease. This is not easy to explain, but there have been frequent reports of a preponderance of male to female patients with motor neuron disease ${ }^{2122}$ and the average age at onset is generally higher in females than in males. ${ }^{22}$

Cortical atrophy in different subtypes of motor neuron disease was especially evident in the cases with signs of involvement of corticobulbar and corticospinal pathways. This suggests that cortical atrophy may be related to the diminution of giant cells of Betz, or to degeneration of pyramidal tracts. ${ }^{8}$ The possibility also exists that various other neuronal populations, functionally related to pyramidal cells, may degenerate, through mechanisms of transynaptic anterograde or retrograde degeneration. ${ }^{23}$ These facts could give some support to the view that motor neuron disease is not confined exclusively to the voluntary motor system ${ }^{24}$ though only three cases out of 50 of our series displayed some defect of cognitive functions; two of these showed mild cortical atrophy.

\section{References}

${ }^{1}$ Bertrandt I, Van Bogaert L. Rapport sur la SLAanatomie pathologique. Rev Neurol (Paris) 1925;6:806-11.

${ }^{2}$ Davison C. Amyotrophic lateral sclerosis: origin and extent of the upper motor neuron lesion. Arch Neurol Psych 1941;46:1039-56.

${ }^{3}$ Friedman AP, Freedman D. Amyotrophic lateral sclerosis. J Nerv Ment Dis 1950;3:1-18.

${ }^{4}$ Wolfart G, Swank RL. Pathology of ALS: fiber analysis of the ventral roots and pyramidal tracts of the spinal cord. Arch Neurol Psych 1941;46:783-99.

${ }^{5}$ Lawyer T, Netsky MG. Amyotrophic lateral sclerosis: a clinicoanatomic study of 53 cases. Arch Neurol Psych 1953;69:171-92.

${ }^{6}$ Smith MC. Nerve fibre degeneration in the brain in amyotrophic lateral sclerosis. J Neurol Neurosurg Psychiatry 1960;23:269-82.

${ }^{7}$ Brownell B, Oppenheimer DR, Hughes JT. The central nervous system in motor neuron disease. J Neurol Neurosurg Psychiatry 1970;33:338-57.

${ }^{8}$ Hammer RP, Tomiyasu U, Scheibel AB. Degeneration of the human Betz cell due to amyotrophic lateral sclerosis. Exp Neurol 1979;63:336-46.

${ }^{9}$ Scheibel ME, Tomiyasu U, Scheibel AB. The aging human Betz cell. Exp Neurol 1977;56:598-609.

${ }^{10}$ Barron SA, Jacobs L. Changes in size of normal lateral ventricles determined by Computed Tomography during aging. Neurology (Minneap) 1976;26:1011-3.

" Jacoby RJ, Levy R, Dawson JM. Computed Tomography in the elderly: I the normal population. Br J Psychiatry 1980;136:249-55.

${ }^{12}$ Wu S, Schenkenberg T, Douglas Wing S, Osborn AG. Cognitive correlates of diffuse cerebral atrophy determined by computed tomography. Neurology (NY) 1981;32:1180-4.

${ }^{13}$ Roberts MA, Caird FI. Computerized Tomography and intellectual impairment in the elderly. J Neurol Neurosurg Psychiatry 1976;39:986-9.

${ }^{14}$ Earnest MP, Heaton RK, Wilkinson WE, Manke WF. Cortical atrophy, ventricular enlargement and intellectual impairment in the aged. Neurology (Minneap) 1979;29:1138-43. 
${ }^{15}$ Huckman MS, Fox J, Topel J. The validity of criteria for the evaluation of cerebral atrophy by Computed Tomography. Radiology 1975;116:85-92.

${ }^{16}$ Becker H, Schneider E, Hacker H, Fischer PA. Cerebral atrophy in Parkinson's disease-represented in CT. Arch. Psychiatr und Nervenkrank 1979;227:81-8.

${ }^{17}$ Pedersen L, Gyldensted C. Computerised tomography in hereditary ataxias. Acta Neurol Scand 1978;58:818.

${ }^{18}$ Engel WK. Motor neuron disorders. In: Goldensohn ES, Appel SH, eds. Scientific Approaches to Clinical Neurology. Philadelphia: Lea and Febiger 1977:132246.

19 Jacoby R, Levy R. Computed tomography in the elderly: (2) senile dementia. Diagnosis and functional impairment. Br J Psychiatry 1980;136:256-69.
${ }^{20}$ Hubbard BM, Anderson JM. Age, senile dementia and ventricular enlargement. J Neurol Neurosurg Psychiatry 1981;44:631-35.

${ }^{21}$ Juergens SM, Kurland LT, Okazaki H, Mulder DW. ALS in Rochester, Minnesota, 1925-1977. Neurology (Minneap) 1980;30:463-70.

${ }^{22}$ Rosen AD. Amyotrophic lateral sclerosis. Arch Neurol 1978;35:638-42.

${ }^{23}$ Smith BH, Arnason B. Pathology of neuron-target cell interactions. Neurosci Res Progr Bull 1977;14:360-6.

${ }^{24}$ Hudson AJ. Amyotrophic lateral sclerosis and its association with dementia, Parkinsonism and other neurological disorders: review. Brain 1981;104:21747. 